\title{
Vitamin A deficiency in treated cystic fibrosis: case report
}

\author{
M O'DONNELL AND J F TALBOT \\ From the Department of Ophthalmology, Royal Hallamshire Hospital, Glossop Road, Sheffield S10 2JF
}

SUMMARY We describe a patient with cystic fibrosis and hepatic involvement who, although on pancreatic extract, developed vitamin A deficiency, night blindness, and a characteristic fundus picture. All of these abnormalities were reversed by oral vitamin A supplementation.

Vitamin A deficiency has been reported in patients with untreated cystic fibrosis. ' We report a patient on adequate pancreatin supplements without vitamin $A$ who developed Vitamin A deficiency and night blindness. In this case cystic fibrosis was complicated by focal biliary fibrosis.

\section{Case report}

An 18-year-old black girl presented in October 1985 to the ophthalmic clinic complaining of difficulty in seeing in dim lights for some months. She had been diagnosed as having cystic fibrosis at the age of 8 months. In November 1983, when in hospital for investigation of dyspnoea and iron deficiency anaemia, an abnormal liver ultrasound scan suggested infiltrative disease. Laparotomy was therefore performed, which showed diffuse irregular abnormality of the liver with scarring. Liver biopsy showed focal biliary and early multilobular cirrhosis (Figs. 1, 2 ) secondary to cystic fibrosis. Endoscopy at this time showed two low pressure oesophageal varices. After this admission to hospital the patient had intermittent problems with gastritis and postprandial abdominal distension. She was maintained on 14 Nutrizym (pancreatin and oxbile extract) tablets per day, acetylcysteine three times a day, Ketovite (multivitamin), Fortical (glucose drink), and the occasional addition of cimetidine.

Ophthalmic examination revealed on presentation visual acuities of $R 6 / 12, \mathrm{~L} 6 / 5$. There was no conjunctival or corneal xerosis; an inferonasal iris

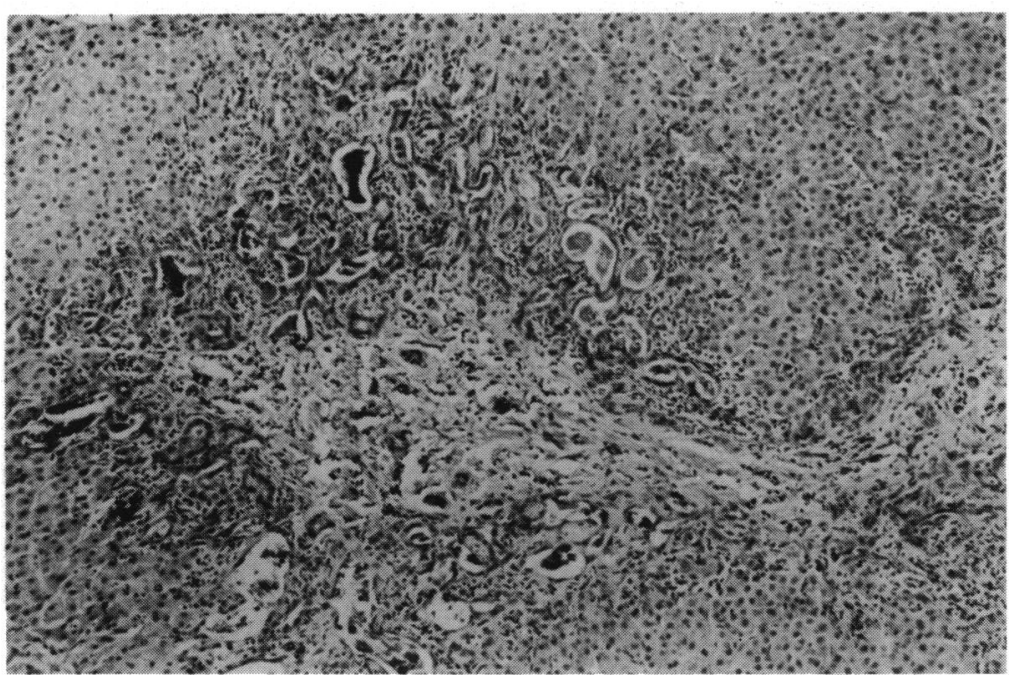

Fig. 1 Liver biopsy. Periportal fibrosis with ductular proliferation typical of hepatic involvement in cystic fibrosis. Haematoxylin and eosin. 
Fig. 2 Liver biopsy. Note gross degree of periportal fibrosis. Masson trichrome.

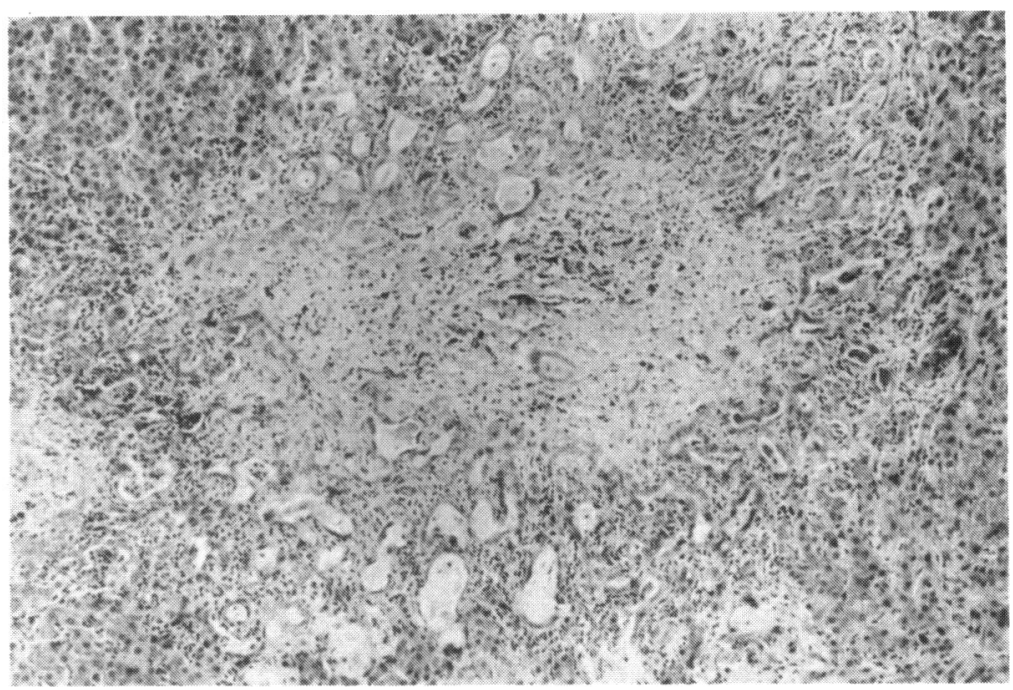

coloboma was present in the right eye. Intraocular pressures were normal. Examination of the fundus showed very many discrete grey-white spots at the level of the retinal pigment epithelium (Fig. 3).

Goldmann perimetry showed mild peripheral constriction. An electroretinogram (ERG) showed depressed B wave amplitudes (Fig. 5). The electrooculogram (EOG) showed a reduced Arden index of $136 \cdot 5(n=>180)$. Dark adaptation with a Goldmann Weeks Adaptometer showed an elevated final rod threshold (Fig. 6).

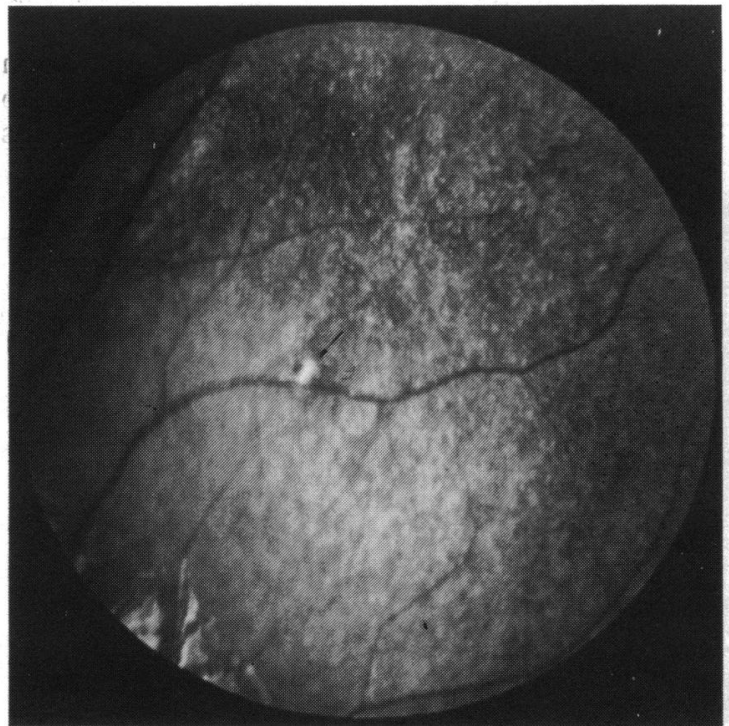

Fig. 3 Fundus photograph. Superotemporal area left eye. Grey-white spots at the level of the retinal pigment epithelium. Note area of retinal pigment epithelial atrophy which serves as a marker (arrow).
Laboratory studies included haemoglobin $9 \cdot 8 \mathrm{~g} / \mathrm{dl}$, white cell count $3.8 \times 10^{\%} / 1$, haematocrit (packed cell volume) $(0 \cdot 30$, mean corpuscular volume $79 \mathrm{fl}$, mẹan corpuscular haemoglobin $25.4 \mathrm{pg}$, mean corpuscular haemoglobin concentration $32.3 \mathrm{~g} / \mathrm{dl}$, urea $2 \cdot 5$ $\mathrm{mmol} / \mathrm{l}$, urate $2.2 \mu \mathrm{mol} / \mathrm{l}$, total protein $8.5 \mathrm{~g} / \mathrm{dl}$, albumin $3.5 \mathrm{~g} / \mathrm{dl}$, globulin $5.0 \mathrm{~g} / \mathrm{dl}$, retinol binding protein $8 \mathrm{mg} / \mathrm{l}$, and prealbumin $0.08 \mathrm{~g} / \mathrm{dl}$. The carotene level was depressed at $0.44 \mu \mathrm{mol} / \mathrm{l}$ (normal $0.93-3.7 \mu \mathrm{mol} / \mathrm{l})$, retinol was very low at $<0.1 \mathrm{mg} / \mathrm{l}$. Liver function tests were also abnormal, with bilirubin raised at $36 \mu \mathrm{mol} / \mathrm{l}$, serum glutamic oxaloacetic transaminase $100 \mathrm{U} / \mathrm{l}$, serum glutamic

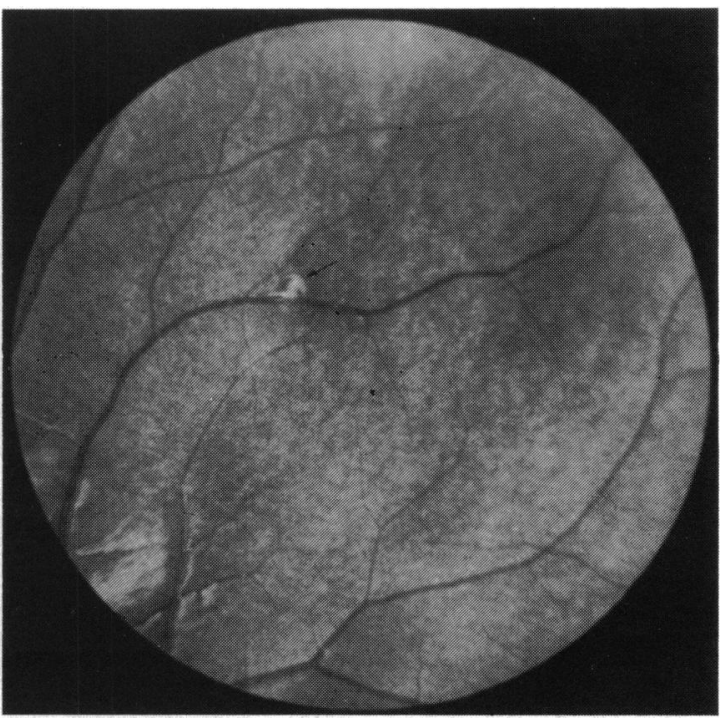

Fig. 4 Fundus photograph. Four months after start of vitamin A therapy. Grey-white spots much less in evidence. 
pyruvic transaminase $86 \mathrm{U} / \mathrm{l}$, gamma glutamyl transpeptidase $56 \mathrm{U} / 1$, and alkaline phosphatase also raised at $356 \mathrm{U} / \mathrm{l}$.

The patient was started on vitamin A therapy. An initial intramuscular injection of vitamin A $30000 \mathrm{IU}$ was given accompanied by vitamin A tablets $5000 \mathrm{IU}$ three times a day for one month, which was later reduced to one tablet per day.

Two months after starting treatment she stated that her night vision was improved. Fundus examination showed a decrease in the amount of grey-white spots (Fig. 4). Electrodiagnostic tests were repeated four months after first presentation and were markedly improved. The ERG showed normal B wave amplitudes (Fig. 5). The Arden index had improved to 261.36; repeated dark adaptation showed the final threshold returning to normal (Fig. $6)$. The serum retinol had improved to $0 \cdot 17 \mathrm{mg} / \mathrm{l}$.

\section{Discussion}

Vitamin A deficiency is nowadays rarely seen in cystic fibrosis owing to more effective therapy for increasing intestinal absorption. A consideration of the metabolism of vitamin A makes it clear how the deficiency may arise in cystic fibrosis patients. Normal dietary sources of vitamin $\mathrm{A}$ are $\beta$-carotene
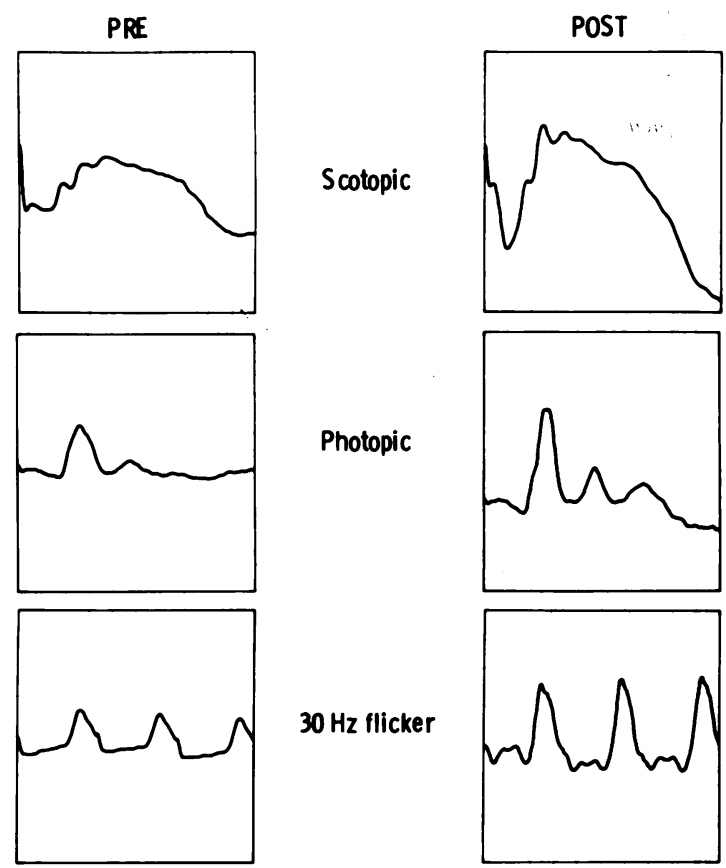

\section{$30 \mathrm{~Hz}$ flicker}

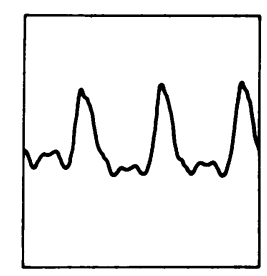

Fig. 5 Electroretinograms. Before and after vitamin A therapy. Improvement of $B$ wave amplitudes following treatment. from plants and vitamin $\mathrm{A}$ itself from animal tissue. $\beta$-Carotene is converted to vitamin A alcohol (retinol) in the body. Animal vitamin A may exist in either alcohol or ester forms. Transport from the intestine is via chylomicra to the liver, where vitamin $A$ is stored as a retinyl ester. The liver is a major store of vitamin A, and it may be some months before a deficiency state becomes manifest. The vitamin is transported in the plasma from the liver to the tissues as an alcohol bound to a transport protein, retinol binding protein (RBP), which is itself complexed with prealbumin. Retinol binding protein is synthesised in the liver. Vitamin A metabolism may be interfered with at both intestinal and hepatic sites in patients with cystic fibrosis.

At necropsy in patients with cystic fibrosis hepatic involvement is seen in $15-20 \%$ of cases. The typical

\section{DARK ADAPTATION}
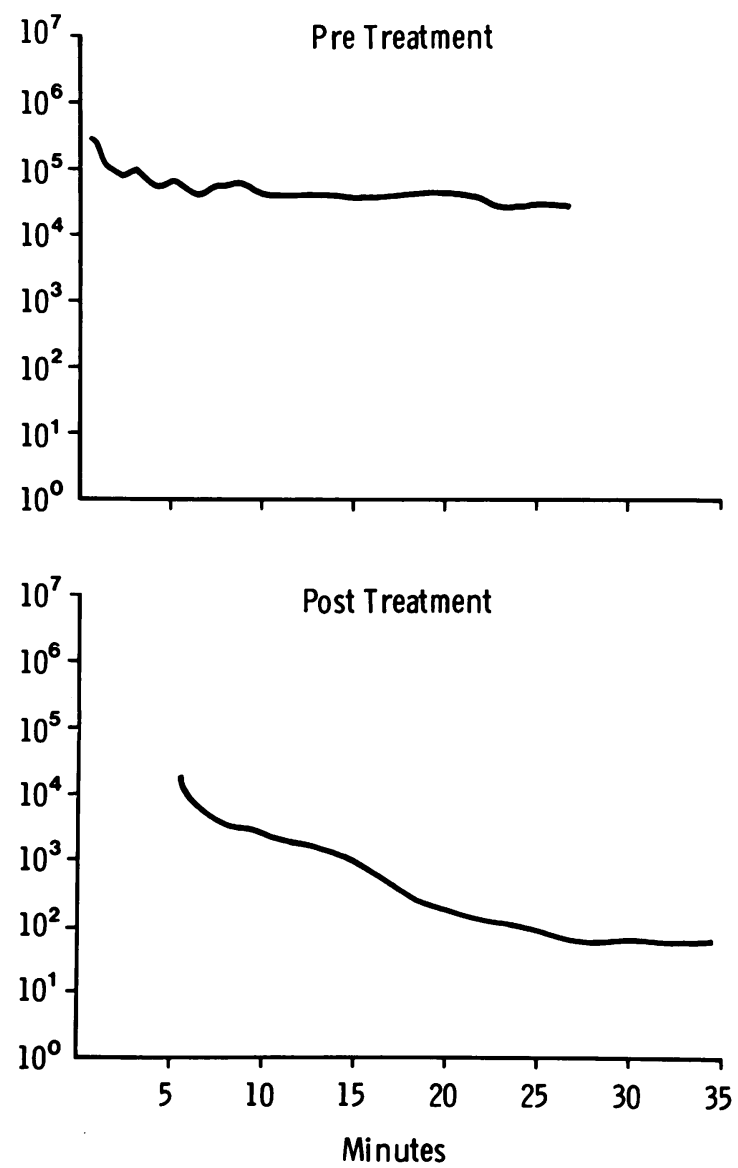

Fig. 6 Dark adaptation studies before and after vitamin A therapy. Decrease in final threshold with treatment is clearly seen. 
lesion seen is a periportal fibrosis (also called focal biliary fibrosis). This may be accompanied by ductular proliferation. These lesions are well demonstrated in the liver biopsy from our patient. Progression of this process may lead to multinodular biliary cirrhosis. Patients with hepatic involvement in cystic fibrosis tend to develop vitamin A deficiency as the excess faecal bile acid is compounded by impaired bile acid synthesis.

That this patient did not have conjunctival xerosis is not unexpected, since such changes have been shown to be preceded by a fall in vitamin A levels and deterioration in dark adaptation. ${ }^{2}$

Vitamin A deficiency has been well documented in other types of liver cirrhosis, ${ }^{34}$ especially primary biliary cirrhosis. Walt et al. ${ }^{3}$ described three patients with late primary biliary cirrhosis and night blindness which responded to vitamin A therapy, while Russell et al. ${ }^{4}$ described abnormal dark adaptation in 26 patients with alcohol related cirrhosis which improved following vitamin A supplementation.

Petersen et al. ${ }^{5}$ described a patient with cystic fibrosis, night blindness, and xerophthalmia. In this instance the patient had failed to take pancreatic extract, and its reintroduction was sufficient to reverse the ocular abnormalities. Our patient in contrast was on full pancreatic supplementation and required added vitamin $A$.

The nature of the white spots seen in the retinal pigment epithelium of vitamin A deficient subjects is not known. Sorsby et al. ${ }^{6}$ produced similar lesions in rabbits fed a vitamin A deficient diet. Histologically they appeared in the periphery, only later spreading centrally. They proved irreversible on intensive vitamin A therapy. The lesions in our patient and in a case described by Bors and Fells' showed improvement of the fundus lesions with treatment.

All patients with hepatic involvement in cystic fibrosis should be on vitamin A supplement.

We thank the Department of Medical Illustration, Lawrence Brown and Margaret Saynor in the Retinal Photography Department, and Debbie Kirk for typing this manuscript.

\section{References}

1 Andersen DH. Cystic fibrosis of the pancreas, Vitamin A deficiency and bronchiectasis $J$ Pediatr 1939; 15: 763-71.

2 Hume EM, Krebs HA. Vitamin A requirement of adult humans: an experimental study of vitamin A deprivation in man. A report of the vitamin A subcommittee of the accessory food factors committee. Spec Rep Ser Med Res Coun 1949; 264.

3 Walt RP, Kemp CM, Lyness L, Bird AC, Sherlock S. Vitamin A treatment for night blindness in primary biliary cirrhosis. Br Med J 1984; 288: 1031-2.

4 Russell RM, Morrison SA, Smith FR, Oaks EV, Carney EA. Vitamin A reversal of abnormal dark adaptation in cirrhosis effects on the plasma retinol transport system. Ann Intern Med 1978; 88: 622-6.

5 Petersen RA, Peterson VS, Rubb RA. Vitamin A deficiency with xeropthalmia and night blindness in cystic fibrosis. Am J Dis Child 1968; 116: 662-5.

6 Sorsby A, Reading HW, Bunyan J. Effect of vitamin A deficiency on the retina of the experimental rabbit. Nature 1966; 210: 1011-5.

7 Bors F, Fells P. Reversal of the complications of self-induced vitamin A deficiency. Br J Ophthalmol 1971; 55: 210-4.

Accepted for publication 28 October 1986. 